\title{
Eritema pigmentado fijo ampolloso medicamentoso relacionado con el uso de ivermectina en paciente con Neumonía por SARS-Cov-2: Reporte de caso
}

\section{Drug-related bullous fixed pigmented erythema related to the use of ivermectin in a patient with SARS-Cov2 pneumonia: Case Report}

\section{DOI}

Edi William Aguilar-Urbina ${ }^{1,2, a}$, Carlos Plasencia-Meza ${ }^{1,2, b}$, Manuel ChávezRimarachin ${ }^{1,3, \mathrm{~b}}$, Regina Aquino-Salverredy ${ }^{1,2, \mathrm{~b}}$, Anghelo Velásquez-Ojeda ${ }^{1, c}$, Carlos Bazán-Gallo ${ }^{1, d}$, Karen Pulido-Aguilar ${ }^{1, e}$, Lorena López-Balarezo ${ }^{1, f}$

https://doi.org/10.35434/rcmhnaaa.2021.143.1280

\section{RESUMEN}

Introducción: El eritema pigmentado fijo ampolloso, es una forma de toxicodermia potencialmente grave. Se caracteriza por la aparición de lesiones cutáneas y/o mucosas, únicas o múltiples, pueden aparecer en cualquier zona, tras la administración de un fármaco u otra sustancia. Se presenta un varón de 73 años con diagnóstico de eritema pigmentado fijo ampolloso secundario a la ingesta de ivermectina. Es necesario que el medico sepa reconocer los efectos adversos de la automedicación con ivermectina contra el SARS CoV-2, a fin de realizar un diagnóstico temprano e iniciar un tratamiento oportuno.

Palabras Clave: Eritema fijo pigmentado ampolloso, toxicodermia, eritema pigmentario medicamentoso (Fuente: DeCS-BIREME).

\section{ABSTRACT}

Background: Bullous fixed pigmented erythema is a potentially serious form of toxicoderma. It is characterized by the appearance of cutaneous and / or mucosal lesions, single or multiple, which can appear in any area, after the administration of a drug or other substance. A 73-year-old man is presented with a diagnosis of bullous fixed pigmented erythema secondary to the ingestion of ivermectin. It is necessary for the physician to recognize the adverse effects of self-medication with ivermectin against SARS CoV-2, to make an early diagnosis and initiate timely treatment.

Keywords:Bullous pigmented fixed erythema, toxicoderma, drug erythema pigmentation. (Source: DeCS-BIREME).

\section{FILIACIÓN}

1. Hospital Regional Docente de Trujillo, La Libertad, Perú.

2. Universidad Nacional de Trujillo, La Libertad, Perú.

3. Universidad Antenor Orrego, La Libertad, Perú.

a. Especialista en Enfermedades Infecciosas y Doctor en medicina.

b. Especialista en Medicina interna, Magister en medicina.

c. Especialista en Nefrología.

d. Residente de Medicina Interna

e. Residente de Cardiología

f. Residente de Neurología

\section{ORCID}

1. Edi William Aguilar-Urbina / 0000-0001-6510-5346

2. Carlos Plasencia Meza / 0000-0001-7398-6219

3. Manuel Chávez Rimarachín / 0000-0003-1229-0036

4. Regina Aquino Salverredy / 0000-0001-9769-9978

5. Anghelo Velásquez Ojeda / 0000-0003-4071-3913

6. Carlos Bazán Gallo / 0000-0002-5319-8271

7. Karen Pulido Aguilar / 0000-0002-2772-9681

8. Lorena López Balarezo / 0000-0002-6683-2569

\section{CORRESPONDENCIA}

Edi William Aguilar Urbina

Dirección: Manzana 0, lote 7, urbanización los portales de la Rinconada. Trujillo. Perú. Teléfono: 996566112

EMAIL

william_aguilar1@hotmail.com

\section{CONFLICTOS DE INTERÉS}

Los autores niegan conflictos de interés.

\section{FINANCIAMIENTO}

Autofinanciamiento.

\section{REVISIÓN DE PARES}

Recibido: 20/08/2021

Aceptado: 10/09/2021

\section{COMO CITAR}

Aguilar-Urbina, E., Plasencia-Meza, C., Chávez-Rimarachin, M., Aquino-Salverredy, R., Velásquez-Ojeda, A., Bazán-Gallo, C., Pulido-Aguilar, K., \& López-Balarezo, L. Eritema pigmentado fijo ampolloso medicamentoso relacionado con el uso de ivermectina en paciente con Neumonía por SARS-Cov-2: Reporte de caso. Revista Del Cuerpo Médico Hospital Nacional Almanzor Aguinaga Asenjo, 2021,14(3), 394 - 397. https://doi.org/10.35434/rcmhnaaa.2021.143.1280

Esta obra está bajo una Licencia Creative Commons Atribución 4.0 Internacional.

Versión Impresa: ISSN: 2225-5109

Versión Electrónica: ISSN: 2227-473

Cross Ref. DOI: 10.35434/rcmhnaaa

OJS: https://cmhnaaa.org.pe/ojs 


\section{INTRODUCCIÓN}

El eritema pigmentado fijo ampolloso, es una forma de toxicodermia potencialmente grave, se caracteriza por la aparición de lesiones cutáneas y/o mucosas, únicas o múltiples, recurrentes siempre en la misma localización, tras la administración de un fármaco o, menor frecuencia, tras la ingesta de otras sustancias, como colorantes alimenticios o la quinina del agua tónica ${ }^{(1,2)}$. Los medicamentos más frecuentemente son sulfonamidas y antiinflamatorios no esteroideos $^{(3)}$.

Las lesiones afectan principalmente a extremidades, genitales y cara, siendo frecuente la afectación del glande, aunque pueden aparecer en cualquier zona. Se inician días después de la ingesta del fármaco, pero pueden presentarse en escasas horas en el individuo previamente sensibilizado. La lesión temprana característica es una mácula bien delimitada, de forma redondeada u ovalada, inicialmente eritematosa, adquiriendo después una tonalidad violácea. Las lesiones se tornan edematosas, y pueden evolucionar hasta convertirse en ampollas o erosiones ${ }^{(1)}$. Habitualmente son asintomáticas, aunque pueden presentar prurito o dolor, especialmente si afectan a mucosas o si presentan erosiones. La fisiopatología del eritema pigmentado fijo ampolloso, se caracteriza por apoptosis de queratinocitos mediada por FasFas ligando ${ }^{(4)}$. Es importante conocer esta reacción medicamentosa, ya que la persistencia en la ingesta del fármaco desencadenante puede aumentar el número y tamaño de las lesiones, ocasionar pigmentación residual o denudación mucosa. Una anamnesis con hincapié en la toma de fármacos es clave en el diagnóstico.

Tras la suspensión del fármaco causal las lesiones desaparecen en los siguientes días, proceso que puede acelerarse con la aplicación de un corticoide tópico potente ${ }^{(1)}$. La pigmentación marronácea residual puede tardar semanas en desaparecer.

Presentamos un paciente con eritema pigmentado fijo ampolloso, secundario a la ingesta de ivermectina; siendo muy importante que el medico sepa reconocer en forma temprana este efecto adverso infrecuente, secundario a la automedicación con ivermectina contra el SARS CoV-2, a fin de realizar un diagnóstico temprano e iniciar un tratamiento oportuno.

\section{REPORTE DE CASO}

Paciente varón de 73 años, casado, de ocupación obrero, lugar de procedencia, Trujillo Perú. Con diagnóstico de enfermedad renal crónica estadio II hace 10 años.

Hace 10 días presenta malestar general, tos seca, por lo cual, se hace la prueba para SARS CoV- 2: resultando positivo, motivo por el cual los familiares le automedican solamente con ivermectina al $6 \%$ : ingiere $1,5 \mathrm{ml}$, dosis única.

A los 2 días posteriores a ingesta de la ivermectina, presenta lesiones cutáneas ampollosas generalizadas, asociadas a prurito, malestar general y escalofríos. El paciente refería que había presentado episodios anteriores similares, con la ingesta de otros medicamentos, los cuales no recuerda nombre. Último episodio, hace un año, con ingesta de paracetamol.

Paciente presenta incremento de dificultad respiratoria y niveles bajos de saturación de oxígeno, es llevado al hospital por emergencia, donde luego de la evaluación clínica y ayudas diagnosticas se concluye en neumonía viral por SARS CoV-2 y lesiones dérmicas múltiples.

En el examen físico presentaba múltiples máculas eritematovioláceas circunscritas, algunas de ellas cubiertas por ampollas flácidas, y erosiones en miembros inferiores y genital (figuras 1y 2).

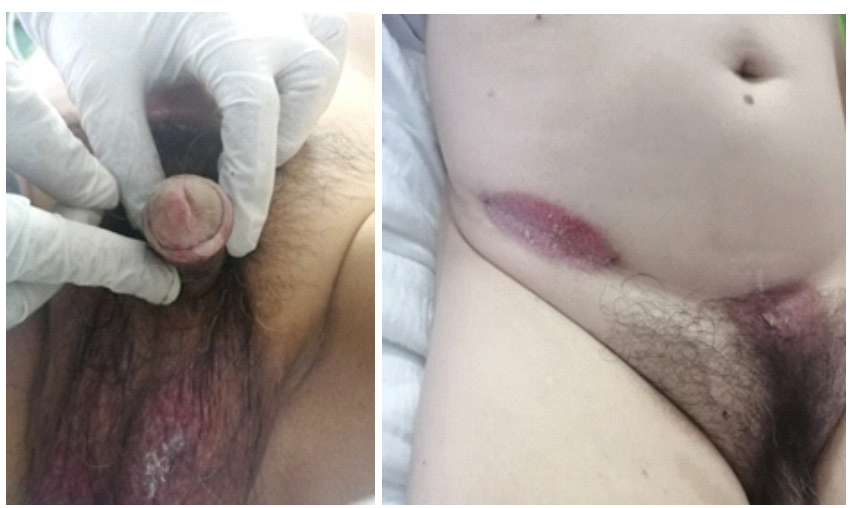

Figura 1.

A) Ampolla flácida en glande. B) Mácula eritemato-violácea en prepucio y escroto; macula eritemato-violácea en abdomen.

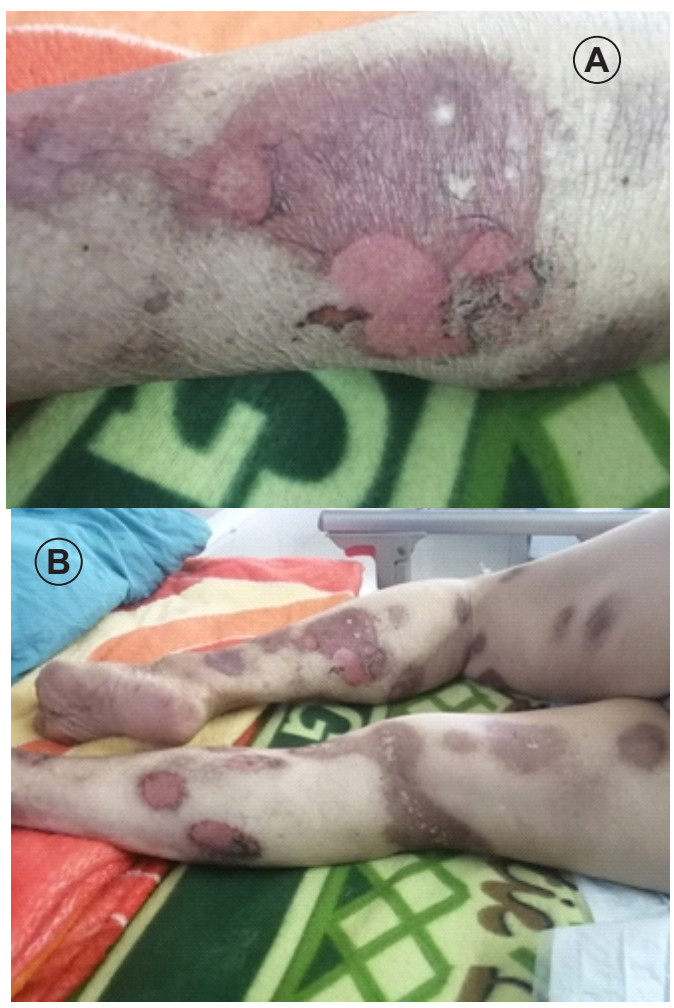

Figura 2.

A) y B) Ampollas flácidas en miembros inferiores 
Tabla 1. Los exámenes de laboratorio al ingreso.

\begin{tabular}{lc} 
EXAMEN & RESULTADO \\
HEMOGRAMA & 1080 \\
& Abastonados: 02 \\
& Segmentados: 88 \\
& Eosinofilos: 00 \\
& Basófilos: 00 \\
& Monocitos: 02 \\
& Linfocitos: 08 \\
HEMOGLOBINA & $11.6 \mathrm{~g} / \mathrm{dl}$ \\
RECUENTO DE PLAQUETAS & 168 \\
GLUCOSA & 100 \\
UREA & 71.8 \\
CREATININA & 1.3 \\
BILIRRUBINAS TOTAL Y FRACCIONADAS & BT: 0.6 BD:0.3 BI:0.3 \\
TGO & 15 \\
TGP & 14 \\
PCR & 118 \\
LDH & 417 \\
\hline
\end{tabular}

Luego de 2 días de hospitalización, fue evaluado por dermatología donde se plantea como posibles diagnósticos: eritema pigmentado y necrólisis epidérmica toxica. Se sugirió tratamiento con corticoide tópico: mometasona 0,1\% mañana y noche por 7 días y clorfenamina endovenosos; además del protocolo de covid (dexametasona $6 \mathrm{mg}$ por 10 días, entre otros fármacos). Se plantea la biopsia de piel. Las lesiones mejoraron a partir del 5 día de tratamiento con mometasona tópica, como se observan en la figura 3.

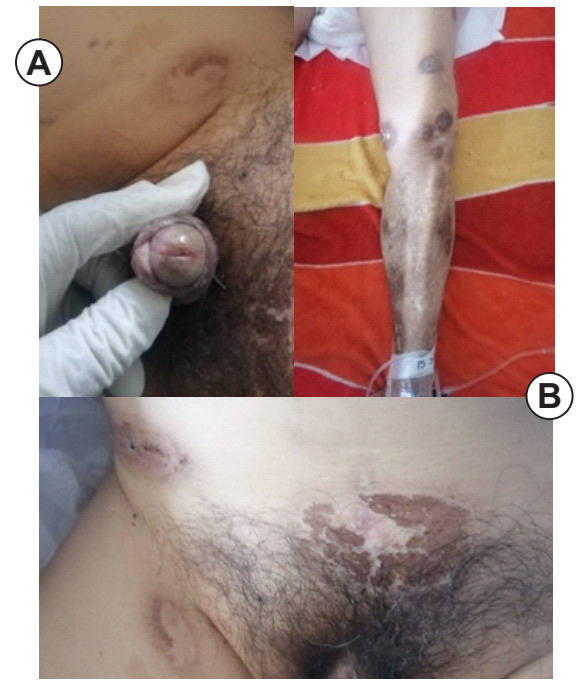

Figura 3.

A) Resolución de la ampolla flácida en glande; B) Máculas violáceas residuales en miembro inferior y abdomen.

Se tomó la biopsia de piel, la cual fue informada como: eritema pigmentado fijo ampolloso (figura 4).

Por las manifestaciones clínicas y el resultado de la histopatología, se llegó al diagnóstico de eritema pigmentado fijo ampolloso. Las lesiones desaparecieron completamente a los 10 días.

Paciente fallece con insuficiencia respiratoria luego de 3 semanas de hospitalizacion.

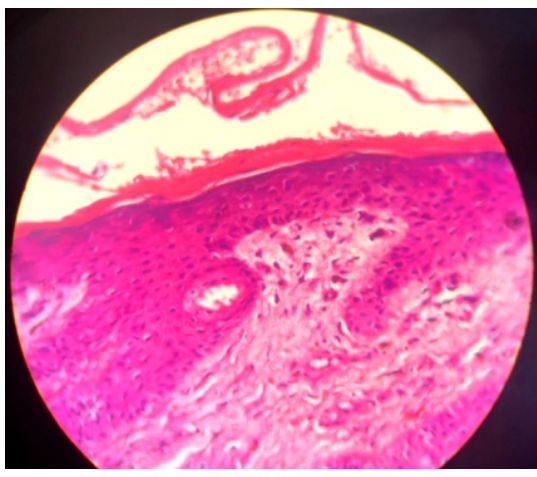

Figura 4.

Moderada a intensa reacción de interfase, desprendimiento de la epidermis en la unión dermoepidérmica y necrosis focal de los queratinocitos. En dermis se observa denso infiltrado linfocitario con eosinófilos y presencia de edema.

\section{DISCUSIÓN}

Las reacciones medicamentosas cutáneas representan el $2 \%$ de las consultas y el $5 \%$ de las hospitalizaciones por dermatología ${ }^{(5)}$. La tasa de mortalidad se encuentra entre 0,1 y $0,3 \% 2$. Son más frecuentes en mujeres y en pacientes inmunosuprimidos $(\mathrm{VIH}$, lupus eritematoso sistémico y linfoma), teniendo estos últimos pacientes 10 a 50 veces más riesgo de desarrollarlas que la población general ${ }^{(5)}$.

Las erupciones fijas medicamentosas se manifiestan como máculas oscuras circunscritas que se resuelven dejando hiperpigmentación residual ${ }^{(1)}$. El sello distintivo es la memoria geográfica ${ }^{(4)}$; y el paciente en mención había presentado episodios similares y en las mismas áreas del cuerpo, esto podría explicarse por la presencia de linfocitos T de memoria residentes en los tejidos que permanecen en la piel por largo tiempo tras la exposición, en este caso, a medicamentos ${ }^{(4)}$. Las lesiones suelen localizarse en el área genital, la mucosa oral, las palmas, las plantas o en cualquier otro sitio anatómico1 (figura 1-3).

El tiempo de aparición oscila entre 30 minutos y 8 horas, o hasta dos días después de la exposición al medicamento; lo cual se corrobora con la clínica que presento el paciente, a los dos días de haber ingerido el fármaco, en este caso, ivermectina.

Existe el antecedente de haber consumido otros fármacos previamente 6 , en el caso reportado se menciona el consumo de paracetamol.

El diagnóstico se basa en la clínica, la histopatología y las pruebas de provocación, tópicas o sistémicas. El tratamiento es sintomático y consiste en la suspensión del medicamento causante y el uso de corticoides tópicos o sistémicos ${ }^{(1,5)}$.

El diagnóstico diferencial debe realizarse con reacciones medicamentosas más graves, como necrólisis epidérmica tóxica o síndrome de Stevens-Johnson debido a extensión, número de las lesiones, y al compromiso mucocutáneo ${ }^{(5)}$.

En el tratamiento es esencial la suspensión inmediata del probable fármaco causal. Además, se requiere un tratamiento sintomático de las lesiones y uso de corticoides 
potentes por vía tópica ${ }^{(7)}$. En nuestro paciente se administró antihistamínicos vía endovenosa y corticoides tópicos, además recibió corticoide endovenoso como parte del tratamiento en paciente con neumonía moderada a severa por SARS CoV-2.

La automedicación con ivermectina puede traer como consecuencia la aparición de un efecto adverso infrecuente como es el Eritema pigmentado fijo ampolloso, la cual es importante tener en cuenta en el diagnóstico diferencial en la evaluación de pacientes con lesiones de gran extensión y aparición recurrente en las mismas zonas de la piel.

\section{REFERENCIAS BIBLIOGRÁFICAS}

1. Flowers $H$, Brodell $R$, Brents $M$, Wyatt J. Fixed drug eruptions: Presentation, diagnosis, and management. South Med J, 107 (2014). 724-727. https://doi.org/10.14423/smj.0000000000000195
2. Genest $G$, Thomson D. Fixed drug eruption to quinine: A case report and review of the literature. J Allergy Clin Immunol Pract, 2 (2014). 469-470.https://doi.org/10.1016/j.jaip.2014.02.013

3. Heng $Y$, Yew $Y$, Lim D, Lim Y. An update of fixed drug eruptions in Singapore. J Eur Acad Dermatol Venereol, 29 (2015). 1539-1544. https://doi.org/10.1111/jdv.12919

4. Choi H, Ku J, Kim M, Kang H, Cho S, Kim H, et al. Possible role of Fas/Fas ligand-mediated apoptosis in the pathogenesis of fixed drug eruption.Br J Dermatol, 154 (2006). 419-425. https://doi.org/10.1111/j.1365-2133.2005.07057.x

5. Revuz J, Valeyrie-Allanore L. Drug reactions. In: Bolognia JL, Jorizzo JL, Schaffer JV, editors. Dermatology. Third edition. London: Elsevier Saunders; 2012. 335-56.

6. Mejia A, Henriquez $\mathrm{O}$, Ivermectin-induced fixed drug eruption: a rare adverse event. INNOVARE. Revista de Ciencia y tecnología. 2021,10 (1). https://doi.org/10.5377/innovare.v10i1.11414

7. Giraldo L, Cajamarca J, Espinoza S, Mora O. Eritema pigmentado fijo ampolloso generalizado. Rev Asoc Colomb Dermatol. 2016; 24 (3): 206-208. 